\title{
PEMBERDAYAAN PENGASUH LANSIA \\ DALAM MENINGKATKAN KUALITAS HIDUP LANSIA DENGAN MENCEGAH ATAU MENURUNKAN DEPRESI MENGGUNAKAN TERAPI REMINISCENCE PADA LANSIA DI LEMBAGA KESEJAHTERAAN SOSIAL LANJUT USIA (LKS-LU) PANGESTI LAWANG KABUPATEN MALANG INDONESIA
}

\author{
Elizabeth Yun Yun Vinsur $^{1^{*}}$, Anang Nurwiyono \\ ${ }^{1,2}$ Sekolah Tinggi Ilmu Kesehatan Panti Waluya Malang, Indonesia \\ *Email: lizavinsur.LV@gmail.com
}

\begin{abstract}
ABSTRAK
Usia lanjut adalah tahap akhir dari siklus hidup manusia. Pada tahap ini banyak perubahan fisik maupun mental, khususnya kemunduran dalam berbagai fungsi dan kemampuan yang pernah dimilikinya. Mereka masih harus berhadapan dengan kehilangan peran diri, kedudukan sosial, serta perpisahan dengan yang dikasihi. Kondisi tersebut menjadikan usia lanjut rentan mengalami masalah mental, salah satunya adalah risiko depresi. Terapi reminiscence merupakan terapi dalam mencegah maupun menurunkan depresi, harga diri rendah, ketidakberdayaan, keputusasaan, dan isolasi sosial pada lansia. Metode pengabdian masyarakat ini adalah dengan: 1) penyuluhan kesehatan pada pengasuh lansia tentang depresi \& pencegahannya; 2) pelatihan tahapan pelaksanaan reminiscence kepada pengasuh lansia di Lembaga Kesejahteraan Sosial Lanjut Usia (LKS-LU) Pangesti Lawang. Hasil kegiatan menunjukkan ada peningkatan pengetahuan pengasuh lansia dengan skor rata-rata pre-test 76 dan post-test 82 . Peserta sasaran kegiatan (pengasuh lansia) juga mampu mendemonstrasikan terapi reminiscence ke lansia, dengan kegiatan awal dan akhir yaitu skrining status depresi Geriatric Depression Scale (GDS). Pemberian terapi reminiscence pada lansia dengan memberdayakan pengasuh lansia di LKS-LU akan menjangkau lebih banyak lagi lansia dan lebih efektif pelaksanaannya karena mereka yang bersama lansia setiap harinya.
\end{abstract}

Kata Kunci: Terapi reminiscence, Lansia, Pelatihan

\section{A. PENDAHULUAN}

Usia lanjut adalah tahap akhir dari siklus kehidupan manusia. Pada tahap ini banyak perubahan terjadi secara fisik maupun mental, khususnya dalam kemunduran fungsi dan kemampuan yang dimilikinya. Mereka yang berada dalam tahap ini harus berhadapan dengan kehilangan peran diri, kedudukan sosial, serta perpisahan dengan orang yang dikasihinya. Kondisi tersebut menjadikan lansia menjadi lebih rentan untuk mengalami masalah mental, salah satunya adalah depresi (Andayani, 2011). Seiring dengan peningkatan jumlah lansia, meningkat pula jumlah lansia yang mengalami 
depresi (Federal Interagency Forum, 2016). Dalam proses penuaan, depresi bukanlah kewajaran. Depresi adalah gangguan mental yang seharusnya dapat dicegah ataupun diterapi (Huang et al., 2015). Identifikasi dan pengobatan depresi pada lansia adalah penting karena hubungannya dengan peningkatan morbiditas dan mortalitas. Studi menunjukkan depresi pada lansia meningkatkan risiko stroke, gagal jantung dan patah tulang pinggul (WHO, 2015 and Federal Interagency Forum, 2016). Depresi telah ditemukan sebagai penyebab independen dari kecacatan serta berkontribusi terhadap kecacatan dari penyakit fisik primer dengan memperburuk kerusakan fisik. Pada penuaan banyak perubahan organik yang memunculkan pola afektif dan perilaku yang khas, sering secara tidak sengaja dipandang sebagai bagian dari proses penuaan yang normal. Depresi mencakup berbagai masalah mental dan gejala emosional, kognitif, dan perilaku yang terkait. Depresi pada lansia meningkatkan penurunan fungsi yang lebih buruk dari seharusnya dan meningkatkan pemanfaatan layanan kesehatan
(WHO, 2015; Olfson et al., 2016; and Federal Interagency Forum, 2016).

Identifikasi dini dan pengobatan depresi berfungsi untuk mengurangi biaya medis tambahan yang dikeluarkan oleh orang yang mengalami depresi dan mengurangi beban pengasuh yang terkait karenanya pengobatan depresi pada populasi yang rentan ini sangat penting (Huang et al., 2015). Global Burden of Disease Study telah memprediksi bahwa gangguan depresi akan menjadi penyebab utama kecacatan pada tahun 2020 karena dampak signifikan mereka pada fungsi dan kualitas hidup. Di seluruh dunia diperkirakan 350 juta orang menderita depresi. Sekitar 5 juta orang dewasa yang lebih tua di seluruh dunia mengalami depresi yang terlambat tetapi masih tetap tidak diakui dan tidak dilakukan perawatan dengan baik (Huang et al., 2016).

\section{Lembaga Kesejahteraan Sosial} Lanjut Usia (LKS-LU) Pangesti Lawang Kabupaten Malang Indonesia merupakan layanan kesejahteraan social bagi lansia baik pria maupun wanita, dengan memisahkan area untuk pria dan wanita. Setiap kamar 
apapun kelasnya dilengkapi dengan CCTV, sehingga setiap lansia dapat terpantau dengan baik. Pelayanan kesehatan yang diberikan LKS-LU Pangesti Lawang Kabupaten Malang Indonesia kepada lansia meliputi layanan medis dimana setiap minggunya ada dokter mitra yang melakukan pemeriksaan, layanan gizi, layanan ambulan dan layanan fisioterapi. Masalah yang ditemukan saat pengkajian, didapatkan: 1) kurangnya pengetahuan pengasuh lansia tentang depresi dan pencegahannya pada lansia, 2) belum optimalnya kegiatan untuk mencegah ataupun menurunkan depresi pada lansia. Meningkatnya pengetahuan pengasuh lansia tentang depresi dan dampaknya melalui penyuluhan yang disampaikan Tim Pengabdi diharapkan dapat membantu pengasuh lansia dalam memahami pentingnya pencegahan dan penanganan depresi pada lansia dan memiliki bekal salah satu psikoterapi yang dapat dilakukan melalui terapi reminiscence.

\section{B. METODE}

Metode pada PkM ini yaitu dengan melakukan pertemuan dengan pihak pengelola LKS-LU yang diwakili pengelola satu orang dan pengasuh lansia satu orang untuk mendapatkan data terkait permasalahan yang dimiliki dalam perawatan lansia. Tim pengabdi kemudian memberikan tawaran solusi yang telah disepakati pula oleh pihak pengelola LKS-LU, sebagai berikut: 1) memberikan penyuluhan kesehatan tentang depresi dan pencegahannya pada pengasuh lansia. 2) mengajarkan terapi reminiscence dalam mencegah atau menurunkan depresi pada pengasuh lansia. 3) mendampingi pengasuh lansia dalam melakukan pengukuran depresi dan menerapkan terapi reminiscence dalam usaha mencegah atau menurunkan depresi pada lansia.

Tahapan pelaksanaan kegiatan diawali dengan pengukuran pengetahuan pengasuh lansia tentang depresi dan pencegahannya (pre-test) sebelum dilakukan penyuluhan tentang topik tersebut. Tim pengabdi selanjutnya melakukan kegiatan penyuluhan kesehatan tentang depresi dan pencegahannya pada lansia di hari Jumat, 7 Februari 2020. Seusai kegiatan penyuluhan kesehatan, selanjutnya dilakukan diskusi tanya 
jawab dan kegiatan pada hari itu ditutup dengan pengukuran pengetahuan pengasuh lansia tentang depresi dan pencegahannya (posttest).

Pelaksanaan

kegiatan selanjutnya adalah mengajarkan terapi reminiscence dalam mencegah atau menurunkan depresi kepada pengasuh lansia. Kegiatan dilakukan pada hari Jumat, 14 Februari 2020. Tim pengabdi mendemonstrasikan cara pengisian lembar kerja skrining depresi dan tahapan terapi reminiscence kepada para pengasuh lansia.

Pada tanggal 21 Februari 2020, tim pengabdi mendampingi pengasuh lansia untuk melakukan pengukuran depresi pada lansia dan menerapkan terapi reminiscence dalam usaha mencegah atau menurunkan depresi pada lansia. Tim pengabdi pada hari Jumat, 28 Februari 2020 mendampingi pengasuh lansia secara minimal dalam melakukan pengukuran depresi dan melakukan tahapan terapi reminiscence dalam usaha mencegah atau menurunkan depresi pada lansia.

Pelaksanaan kegiatan PkM ini dilakukan dalam durasi 120 menit setiap pertemuannya di aula yang terdapat di LKS-LU. Pengukuran pengetahuan sebelum dan sesudah penyuluhan dilakukan dengan soal pilihan ganda dengan skor maksimal 100. Hasil pengukuran pengetahuan tiap pengasuh lansia dijumlah dan dirata-rata. Pengukuran keefektifan pelatihan dilakukan dengan indikator kualitatif meliputi keaktifan pengasuh lansia (kehadiran minimal 75\%) dan pemberian kesempatan kepada semua pengasuh $(100 \%)$ untuk melakukan skrining depresi pada lansia dan melakukan tahapan reminiscence. Pengukuran skrining depresi pada lansia dilakukan menggunakan kuisioner baku Geriatric Depression Scale.

\section{Hasil dan Pembahasan}

Hasil kegiatan menunjukkan ada peningkatan pengetahuan pengasuh lansia dengan skor rata-rata pre-test 76 dan post-test 82. Keaktifan pengasuh lansia dalam kegiatan $100 \%$ dimana masing-masing pengasuh lansia mendapatkan kesempatan (100\%) untuk mencoba melakukan skrining depresi dan melakukan tahapan reminiscence antar pengasuh. Peserta sasaran kegiatan (pengasuh 
lansia) diakhir kegiatan mampu mendemonstrasikan terapi reminiscence ke lansia, dengan kegiatan awal dan di akhir terapi yaitu skrining status depresi Geriatric Depression Scale (GDS). Pemberian terapi reminiscence oleh Pengasuh kepada para lansia di LKS-LU diharapkan dapat menurunkan risiko depresi pada lansia yang menjadi asuhannya.

González, et al. (2010) mengungkapkan bahwa depresi merupakan salah satu gangguan kejiwaan yang paling sering terjadi pada pasien usia lanjut. Sivertsen et al. (2015) menambahkan bahwa depresi berhubungan dengan peningkatan risiko kematian, prognosa yang buruk untuk pengobatan penyakit fisik, dan depresi juga berpengaruh buruk terhadap kualitas hidup. Upaya peningkatan kesadaran kesehatan mental untuk meningkatkan pemahaman tentang depresi diperlukan di semua lini sebagai upaya meningkatkan akses ke perawatan kesehatan mental yang berkualitas dan perawatan yang efektif; dan untuk penelitian guna mengidentifikasi pengobatan baru dan meningkatkan pengobatan yang ada untuk semua gangguan mental (WHO, 2021). Cuijpers, et al. (2014) mengungkapkan meskipun perlu dilakukan penelitian lebih lanjut dan mendalam tetapi psikoterapi mungkin efektif dalam pengobatan depresi subklinis dan mengurangi kejadian depresi berat.

Hal ini menjadikan praktik nyata dalam pemberian asuhan keperawatan di komunitas terkait perubahan fokus dalam perawatan lansia pada promosi kesehatan diperlukan untuk mencapai kesejahteraan (González, et al., 2010). Klever (2013) menjelaskan bahwa terapi reminiscence adalah intervensi nonfarmakologis yang meningkatkan harga diri dan memberikan rasa kepuasan dan kenyamanan saat mereka yang di usia lanjut melihat kembali kehidupan mereka. Mengenang melibatkan mengingat peristiwa masa lalu, tetapi disini menekankan pada dorongan agar lansia berkomunikasi dan berinteraksi dengan terapis atau pendengar di saat ini. Sesi mengenang dapat dilaksanakan dalam bentuk formal, informal, individu, maupun dalam kelompok. 
Gambar 1. Kegiatan Penyuluhan Kepada Pengasuh Lansia
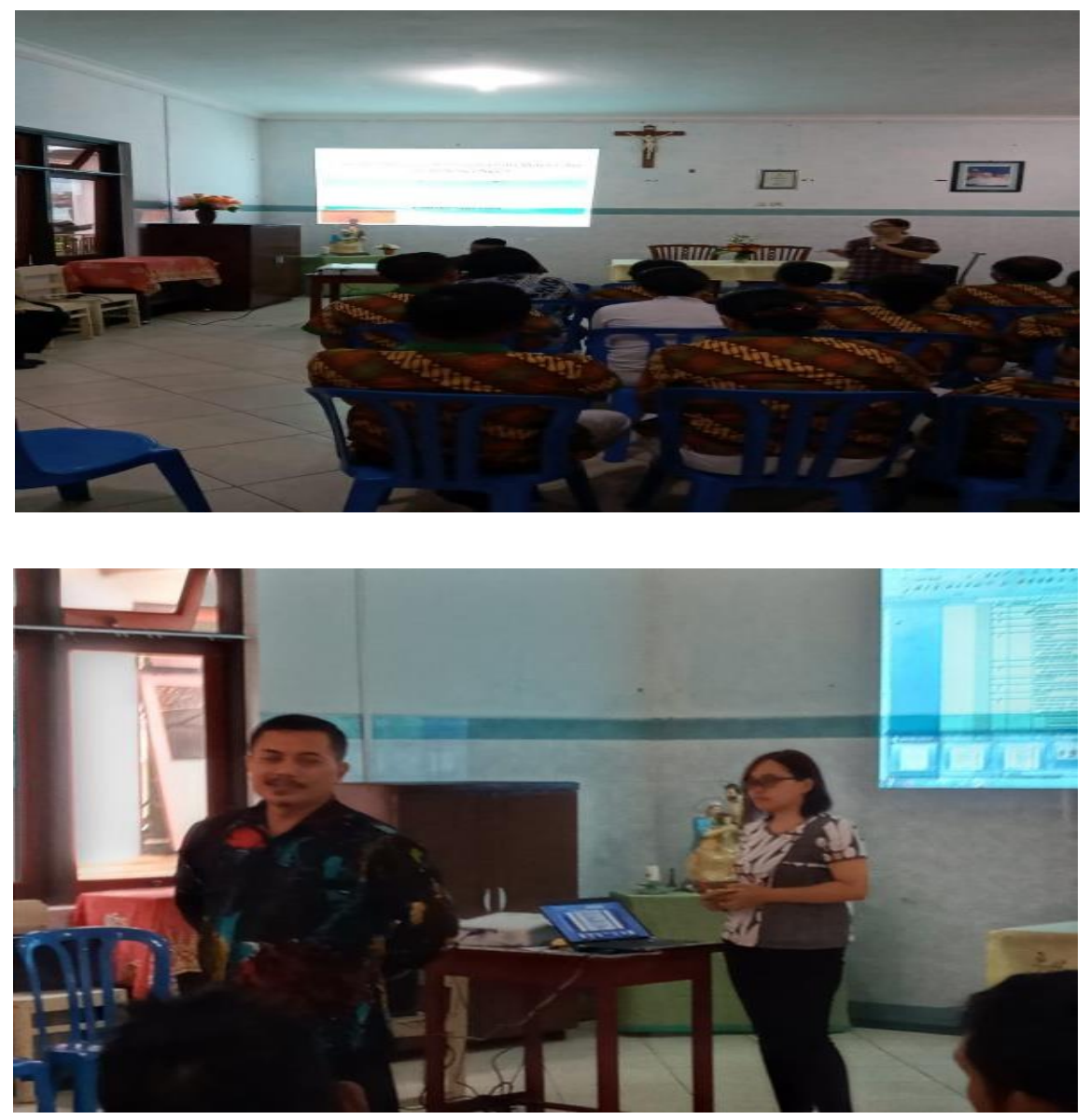

Keterangan: Foto Kegiatan pemberian pengetahuan tentang depresi dan pencegahannya.

Gambar 2. Kegiatan Pelatihan Terapi Reminiscence Kepada Pengasuh Lansia

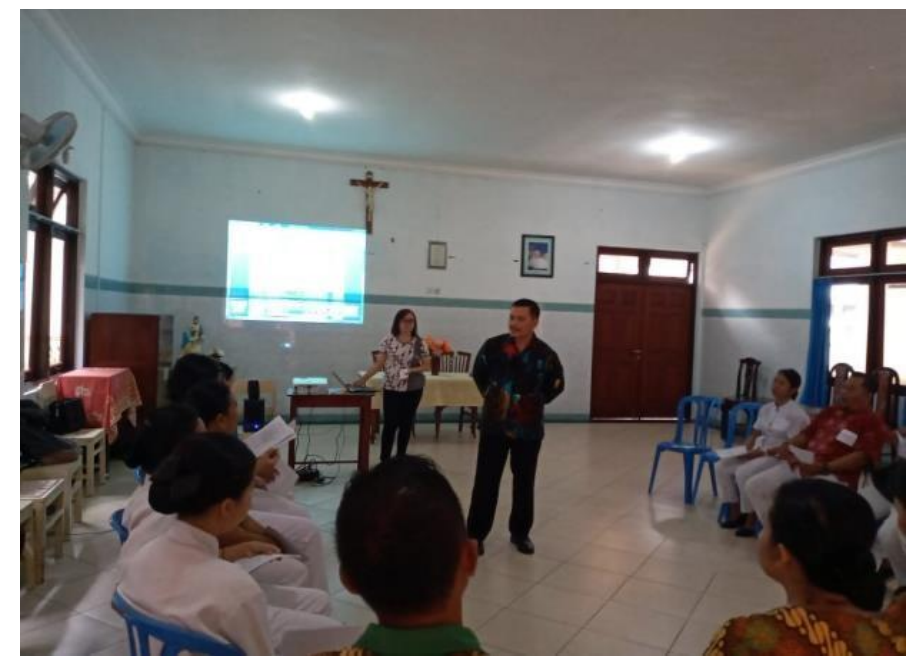

Keterangan: Foto Kegiatan Demonstrasi TAK dengan Terapi Reminiscence 
Gambar 3. Kegiatan penerapan Terapi Reminniscence oleh Pengasuh Lansia

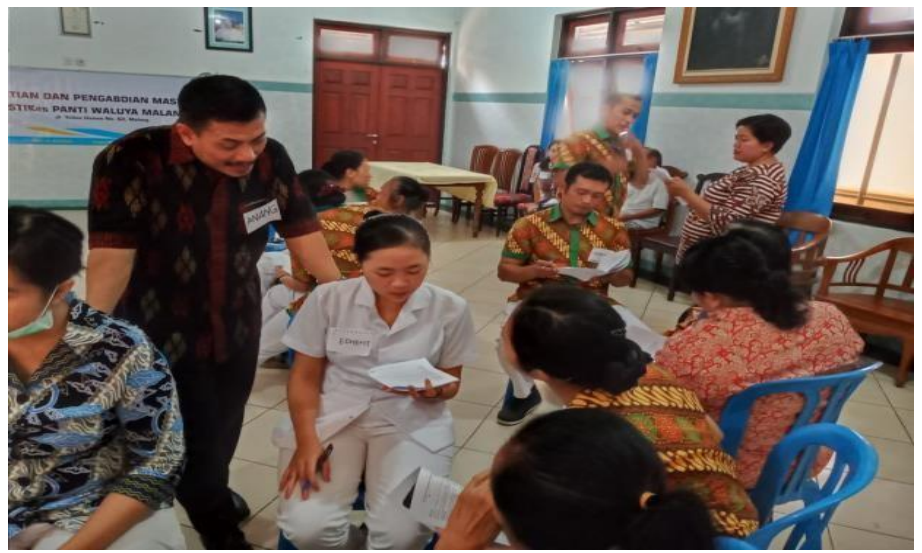

Keterangan: Foto Kegiatan Pengasuh Lansia melakukan skrining depresi didampingi Tim Pengmasy.

Gambar 4. Foto Bersama sebagian Pengasuh Lansia dan sebagian Lansia di Lembaga Kesejahteraan Sosial Lanjut Usia (LKS-LU) Pangesti Lawang

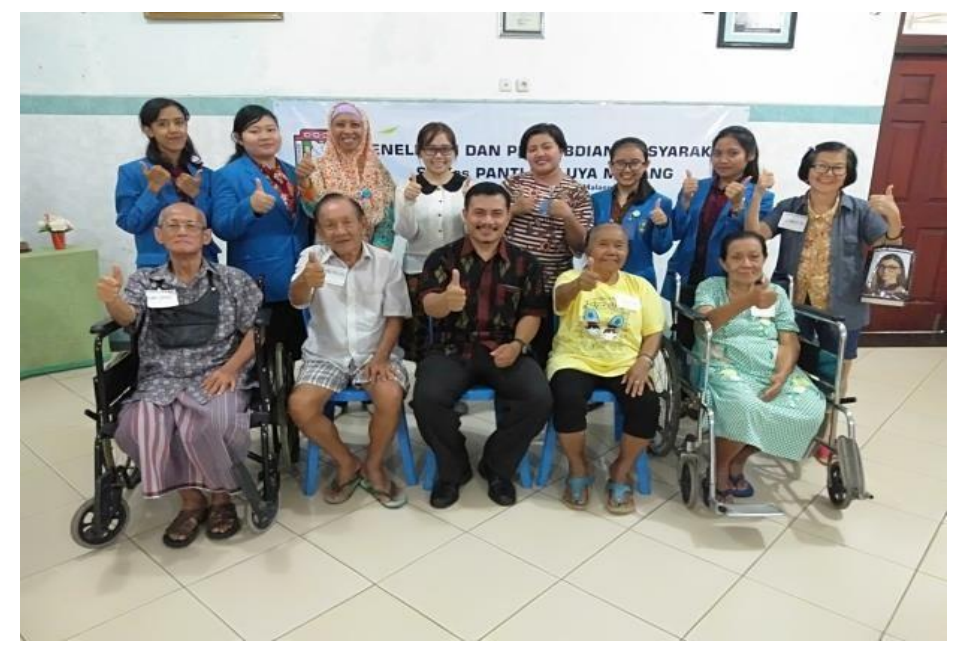

Keterangan: Kegiatan Foto bersama pada sebagian lansia dan pengasuh Lansia di Lembaga Kesejahteraan Sosial Lanjut Usia (LKS-LU) Pangesti Lawang selesai mengikuti terapi reminiscence

\section{Kesimpulan}

Pengasuh lansia berinteraksi setiap harinya dengan lansia di LKS-LU sehingga pengetahuan tentang depresi dan pencegahannya sangatlah penting untuk diketahui. Terapi reminiscence sebagai salah satu terapi dalam mencegah atau menurunkan depresi sangat mudah untuk diterapkan baik sebagai terapi maupun sebagai kegiatan rekreasi bersama para lansia penghuni LKS-LU yang aman dan murah karena tidak perlu keluar. Pemberdayaan pengasuh lansia memungkinkan lansia yang dijangkau tidak terbatas hanya pada lansia yang ada pada saat kegiatan berlangsung. 


\section{DAFTAR PUSTAKA}

Andayani, R. 2011. Buku Ajar Geriatri, Balai Penerbit FKUI: Jakarta, hal. 140150.

Cuijpers, P., Koole, S., Van Dijke, A., Roca, M., Li, J., \& Reynolds, C. (2014). Psychotherapy for subclinical depression: Meta-analysis. British Journal of Psychiatry, 205(4), 268274. doi:10.1192/bjp.bp.113.138784

Federal Interagency Forum on AgingRelated Statistics. (2016). Older Americans.: Key Indicators of WellBeing. Washington, D.C.

González, Luz Angélica Muñoz, Romero, Yocelyn Margaret Price, López, Marcia Reyes, Ramírez, Macarena, \& Stefanelli, Maguida Costa. (2010). The experience of family caregivers of older people with depression. Revista da Escola de Enfermagem da USP, 44(1), 32-39. https://doi.org/10.1590/S0080$\underline{62342010000100005}$

Huang AX, Delucchi K, Dunn LB, et al. (2015). A systematic review and metaanalysis of psychotherapy for late-life depression. Am J Geriatr Psychiatry. 2015; 23:261-73.
Klever, Sandy. (2013). Reminiscence therapy: Finding meaning in memories. Nursing: April 2013 Volume 43 - Issue 4 - p 36-37. doi: 10.1097/01.NURSE.0000427988.239 41.51 .

https://journals.lww.com/nursing/Fullt ext/2013/04000/Reminiscence_therap y_Finding_meaning_in_memories. 1 $\underline{1 . \operatorname{aspx}}$

World Health Organization. (2015). World report on ageing and health. Geneva: Geneva, Switzerland.

World Health Organization. (2021). Mental Health. https://www.who.int/healthtopics/mental-health\#tab=tab_1 diakses 1 April 2021.

Sivertsen H, Bjørkløf G, H, Engedal K, Selbæk G, Helvik A, -S: Depression and Quality of Life in Older Persons: A Review. Dement Geriatr Cogn Disord 2015;40:311-339. https://www.karger.com/Article/Fullte xt/437299\# doi: 10.1159/000437299 